\title{
Fatty Acids in the Portal Vein of the Rat Regulate Hepatic Insulin Clearance
}

Jan Svedberg, Gunnar Strömblad, Alfred Wirth, Ulf Smith, and Per Björntorp

The Wallenberg Laboratory and Departments of Medicine I and II, Sahlgren's Hospital, University of Göteborg, Sweden

\begin{abstract}
The effects of FFA on hepatic insulin clearance were studied in the in situ perfused rat liver. Clearance decreased with increasing body weight (age) of the rats. When FFA were added to the perfusate a $40 \%$ reduction of hepatic removal of insulin was found over the normal, physiological range $(<1,000 \mu \mathrm{mol} /$ liter), less pronounced in heavier rats. When perfusion was started with high concentrations of FFA, inhibition was rapidly reversible, a phenomen again blunted in heavier rats. In contrast to FFA, different glucose concentrations in the perfusate did not affect the hepatic insulin uptake in the presence of FFA within physiological concentrations.

Thus, hepatic clearance of insulin is proportional to rat weight (age) and portal FFA concentrations. Other studies have recently shown that fatty acids inhibit insulin binding, degradation, and function in isolated rat hepatocytes, and that hepatic clearance is inversely dependent on hepatic triglyceride concentrations, both inhibitions reversible by prevention of fatty acid oxidation. It is suggested that the diminished hepatic clearance of insulin in heavier (older) rats is at least partly due to their relative obesity and increased hepatic triglyceride contents. This effect as well as that of portal FFA is probably mediated via fatty acid oxidation in the liver. This mechanism may have implications for the regulation of hepatic metabolism, and peripheral insulin concentrations. (J. Clin. Invest. 1991. 88:2054-2058.) Key words: obesity • liver • perfusion • insulin • FFA
\end{abstract}

\section{Introduction}

It is well established that close associations exist between hyperinsulinemia, peripheral insulin resistance, and perturbed carbohydrate metabolism. Hyperinsulinemia occupies a central position since elevated insulin levels have been shown in direct in vitro experiments to induce insulin resistance in a variety of cells (1). In nonobese subjects the effects of intravenously administered glucose on hepatic insulin clearance has been reported to be dependent on the duration of the stimulus as well as on insulin concentrations (2). Hyperglycemic clamp studies have demonstrated that the insulin clearance is reduced at high insulin levels in response to glucose infusion, indicating that a possible reduction in hepatic insulin clearance is due to the hyperinsulinemia per se rather than the increased glucose

Address correspondence to Dr. Jan Svedberg, The Wallenberg Laboratory, Sahlgrens Hospital, S-413 45 Göteborg, Sweden.

Dr. Wirth's present address is Teutoburger Wald Klinik, $4502 \mathrm{Bad}$ Rothenfelde, Germany.

Received for publication 06 December 1990 and in revised form 09 July 1991.

J. Clin. Invest.

(c) The American Society for Clinical Investigation, Inc. $0021-9738 / 91 / 12 / 2054 / 05 \quad \$ 2.00$

Volume 88, December 1991, 2054-2058 levels, whereas the hepatic clearance is unchanged by glucose infusion at low insulin concentrations (3). This has also been demonstrated during steady-state hyperglycemia and physiologic hyperinsulinemia (4). In obese individuals, a reduction in hepatic insulin extraction under basal conditions has been reported to be present when plasma insulin levels are high (5). The hyperinsulinemia in obese subjects is known to be due to an increased pancreatic insulin secretion, both in the basal state and after glucose stimulation; and there is a significant relationship between basal and glucose-stimulated pancreatic insulin secretion and adiposity, as estimated by percentage body fat or body mass index $(3,6)$.

The distribution of the adipose mass seems to influence the hepatic insulin clearance in the obese state. In obese women there is a significant negative correlation between the abdominal fat mass, as measured by the waist-to-hip girth ratio, and the hepatic insulin clearance, both in the basal and the glucosestimulated state. This reduction in hepatic removal of insulin from the portal vein in abdominally, as compared to gluteofemoral obese women, exists despite the similarity in portal insulin concentrations in both groups studied (6).

The observation that the hepatic extraction of insulin may vary between different patient groups might be of importance for the development of a reduced carbohydrate tolerance. An attenuated clearance can lead to elevated peripheral insulin levels which may cause insulin resistance as discussed above.

Elevated FFA levels are seen in both diabetes and obesity (7) due to an increased lipolysis $(8,9)$. The FFA levels may be even higher in the portal than in the peripheral blood because omental and mesenteric fat cells have an increased response to normal lipolytic hormones $(10,11)$ and their venous blood is drained by the portal vein.

Insulin extraction is a receptor-mediated event (12-14), and may also be related to the metabolic effect of insulin in the liver (13). We recently reported that fatty acids in physiological concentrations inhibit insulin binding, degradation, and function in isolated rat hepatocytes (15), apparently dependent on the oxidation of the fatty acids $(15,16)$.

In the present work we examined the effects of fatty acids on hepatic insulin clearance in the integrated system of the in situ perfused rat liver. The results show that FFA in the physiological concentration range inhibit insulin uptake by the liver. These results have been presented in preliminary form (17).

\section{Methods}

Male Sprague-Dawley rats were kept at constant humidity and temperature $\left(21-23^{\circ} \mathrm{C}\right)$ and with $12 \mathrm{~h}$ light. They had free access to water and commercial rat pellets (Ewos, Södertälje, Sweden) containing by weight $5 \%$ fat, $55 \%$ carbohydrates, and $22.5 \%$ protein with sufficient minerals and vitamins.

Liver perfusion system. After an overnight fast, the rats were anesthetized by the injection of pentobarbital $(50 \mathrm{mg} / \mathrm{kg}$ body wt i.p.). A cannula was inserted into the portal vein for the perfusion, and the perfusate was collected in the superior vena cava. The liver was kept in situ throughout the perfusion $(18,19)$. The perfusion medium consisted of Krebs-Ringer-bicarbonate (KRb) containing 3\% BSA 
(Behringwerke, Marburg, Germany) or essentially fatty acid free albumin (A 6003; Sigma Chemical Co., St. Louis, MO), $5 \mathrm{mM}$ glucose if not stated otherwise, and erythrocytes from outdated donor blood (4-6 wk old) with the hematocrite adjusted to $20 \%$. The human blood was washed three times with an equal volume of $0.9 \% \mathrm{NaCl}$ and finally with $\mathrm{KRb}$. $\mathrm{pH}$ was adjusted to 7.4 with $1 \mathrm{~N} \mathrm{NaOH}$ before the perfusion. Porcine insulin (crystalline, glucagon-free, Eli Lilly Co., Indianapolis, IN) was added at concentrations given for each experiment. Oleic acid (Sigma Chemical Co.) was used as sodium salt and complexed to albumin to give the indicated FFA concentrations in the perfusion medium.

The perfusion system was kept at an environmental temperature of $38^{\circ} \mathrm{C}$. The perfusion medium was pumped at a constant rate $(2.0 \mathrm{ml} /$ min per $\mathrm{g}$ of wet liver) from the reservoir $(40 \mathrm{ml})$ to the lung in a recycling system. The lung consisted of $5 \mathrm{~m}$ silastic tubing of $1.47 \mathrm{~mm}$ inner diameter and $0.25 \mathrm{~mm}$ wall thickness (Dow Corning Corp., Midland, MI) coiled in a jar as described by Hamilton et al. (20). The gas mixture was $99 \% \mathrm{O}_{2}$ and $1 \% \mathrm{CO}_{2}$ which passed the container at a flow rate of 1 liter $/ \mathrm{min}$. After passing the pump again the perfusion fluid entered the portal vein through a needle and was collected in the upper vena cava from a tube, placed $15 \mathrm{~cm}$ below the liver to avoid swelling.

Before addition of insulin to the medium the livers were perfused for $30 \mathrm{~min}$ to achieve a constant oxygen uptake. After addition of insulin, $5 \mathrm{~min}$ were allowed for equilibration, and thereafter insulin disappearance from the medium was measured, by taking samples every $5 \mathrm{~min}$ from the outflow over a period of $25 \mathrm{~min}$. The volume taken was replaced at the end of each perfusion period. Different fatty acid concentrations were obtained by changing perfusion medium.

Functioning livers maintained their even reddish color throughout the entire perfusion period of $2 \mathrm{~h}$. With blotchy appearance of the surface the perfusion pressure also increased and such livers were discarded. In the livers used there was no swelling and the average wet weight/dry weight ratio was 3.0 (range, 2.9-3.2). The perfusion pressure in the portal vein was monitored and ranged from 3 to $15 \mathrm{~cm} \mathrm{H}_{2} \mathrm{O}$. Leakage of potassium into the medium was not detectable. Aspartate aminotransferase (ASAT) and alanine aminotransferase (ALAT) activities rose slightly in the perfusate (from 0.20 and 0.13 to 0.27 and 0.17 $\mu$ kat/liter, respectively, $n=7$ ), $\mathrm{PO}_{2}$ and $\mathrm{PCO}_{2}$ remained essentially constant throughout the perfusion period and was 421 and $52 \mathrm{mmHg}$ in the inflow, and 57 and $65 \mathrm{mmHg}$ in the outflow from the liver, respectively (mean values of eight measurements). This resulted in a mean hepatic $\mathrm{O}_{2}$ consumption of $4.2 \mu \mathrm{mol} / \mathrm{g}$ per min.

Changes in the insulin concentration were calculated in relation to the $5 \mathrm{~min}$ value of insulin concentration. The decay curves followed first order kinetics. Hepatic clearance of insulin was calculated as described before $(18,19)$ on a table computer using linear regression analysis by the method of least squares. Curves with correlation coefficients below 0.95 were rejected. This occurred in $<5 \%$ of the experiments. The hepatic clearance of insulin was calculated from the formula $(K=2.3 / t) \log \left(C_{\mathrm{a}} / C_{\mathrm{f}}\right)$; where $K=$ milliliters perfusion medium cleared of insulin per min, $C_{\mathrm{a}}$ and $C_{\mathrm{f}}$ represent the concentration of insulin at the beginning and at the end of the time interval $\Delta t$, respectively. Values shown are the means \pm SEM.

Chemical analyses. Glucose was determined enzymatically (GLOX, KABI, Stockholm, Sweden), potassium by flame photometry, ASAT and ALAT by routine clinical methods, and $\mathrm{O}_{2}$ and $\mathrm{CO}_{2}$ by selective electrodes (Automated $\mathrm{O}_{2}-\mathrm{CO}_{2}$ analyzer, $\mathrm{ABL} 2$, Radiometer, Copenhagen, Denmark). Free fatty acid concentrations were determined according to Dole (21), and insulin by a solid-phase radioimmunoassay (Phadebas; Pharmacia Fine Chemicals, Uppsala, Sweden).

Liver perfusion experiments. Experiments were first performed to evaluate the reproducibility of the insulin uptake during repeated perfusions of the same liver. The livers were first perfused for $15 \mathrm{~min}$ to achieve a constant oxygen uptake. Thereafter, insulin and glucose were added to the reservoir to give concentrations of $\sim 90 \mu \mathrm{U} / \mathrm{ml}(n=6)$ or $240 \mu \mathrm{U} / \mathrm{ml}(n=4)$ insulin in the perfusion medium and $5 \mathrm{mmol} / \mathrm{liter}$ glucose. No FFA were added and remained constant at $280 \mu \mathrm{mol} / \mathrm{liter}$ throughout the perfusion. This procedure was repeated up to a total of three times with the same livers.
Effect of the glucose concentration. These experiments were performed to evaluate the importance of the glucose concentration for the insulin uptake. After 15 min "basal" perfusion each liver was perfused for $30 \mathrm{~min}$ with each of three different glucose concentrations: 5,10 , and $20 \mathrm{mmol} / \mathrm{liter}$. In half of the experiments, the lowest glucose concentration was used first followed by the higher concentrations, while in the other experiments, the reverse sequence was followed. The FFA concentration was kept constant ( $550 \mu \mathrm{mol} / \mathrm{liter})$ throughout the entire perfusion period by using a perfusion pump delivering sodium oleate at a predetermined flow rate. Before each perfusion period, insulin was added to a concentration of $300 \mu \mathrm{U} / \mathrm{ml}$ in the reservoir $(n=7$ experiments).

Effect of the FFA concentration. These experiments were performed to evaluate the influence of the medium FFA on the insulin uptake. After $15 \mathrm{~min}$ "basal" perfusion, insulin was added to a concentration of $300 \mu \mathrm{U} / \mathrm{ml}$ to the reservoir. The glucose concentration was $5 \mathrm{mmol} /$ liter. Oleic acid concentrations were varied by using different brands of albumin and addition of oleic acid as sodium salt, complexed to albumin. The fatty acid concentration with the albumin from Behringwerke without addition was $280 \mu \mathrm{mol} /$ liter while the Sigma albumin was essentially free from FFA. Oleic acid was added to desired concentrations at the start of experiments, and held constant throughout the experimental period with the help of a perfusion pump as described above. With the fatty acid free albumin used without exogenous fatty acid addition, fatty acid concentrations rose during perfusion. The concentration determined in the perfusate at the end of perfusion is given in Results.

Four different series of experiments were performed as described in the following. (1) Rat weight $310 \pm 4 \mathrm{~g}(n=12)$. Final FFA concentrations were $240 \pm 25$ and $712 \pm 30 \mu \mathrm{mol} /$ liter complexed to FFA-free albumin (Sigma Chemical Co.). Half of the experiments were performed with the lowest FFA concentration first, and half with the highest concentration. (2) Rat weight $460 \pm 5 \mathrm{~g}(n=12)$. FFA concentrations were $350,1,000$, and $2,250 \mu \mathrm{mol} /$ liter, complexed to a FFA-containing albumin (Behringwerke). These concentrations were tested in half the rats starting with the lowest concentration, and the other half starting with the highest concentration. (3) Rat weight $540 \pm 8 \mathrm{~g}(n=5)$. FFA concentrations were 880,230 , and $190 \mu \mathrm{mol} /$ liter, respectively, complexed to albumin as in experiment 2 . Perfusions were performed in the order given for the FFA concentrations. (4) In addition to these rats, in order to test the effect of weight (age), another six rats weighing $540 \pm 9 \mathrm{~g}$ and six rats weighing $200 \pm 5 \mathrm{~g}$ were utilized. FFA concentrations in these experiments were $310 \mu \mathrm{mol} /$ liter and $250 \mu \mathrm{mol} / \mathrm{liter}$, respectively.

\section{Results}

Reproducibility of the insulin clearance measurements. As shown in Fig. 1 the hepatic clearance of insulin at a perfusate concentration of $90 \mu \mathrm{U} / \mathrm{ml}$ was linear on a semilog scale. The clearance (expressed as percent of initial insulin concentration) was $\sim 60-70 \%$ after $10 \mathrm{~min}$, and $10-20 \%$ after $30 \mathrm{~min}$ of perfusion. These experiments also demonstrate that there were no differences in insulin clearance between the repeated perfusions and conditions when the insulin, glucose, and FFA concentrations were unchanged. The same reproducibility was obtained in experiments with $240 \mu \mathrm{U} / \mathrm{ml}$ of insulin in the perfusion medium (not shown).

Effect of glucose on insulin clearance. As shown in Fig. 2, changing the glucose concentrations in the perfusion medium from 5 to 10 and $20 \mathrm{mmol} /$ liter did not influence on the insulin removal by the liver. The insulin clearance was also independent of whether the perfusion was started with the lowest or the highest glucose concentration (not shown).

Effect of rat weight (age) on insulin clearance. Fig. 3 shows the insulin clearance at $5.5 \mathrm{mmol} /$ liter of glucose, $211 \mu \mathrm{U} / \mathrm{ml}$ of insulin and FFA concentrations of 240-350 $\mu \mathrm{mol} / \mathrm{liter}$. All 


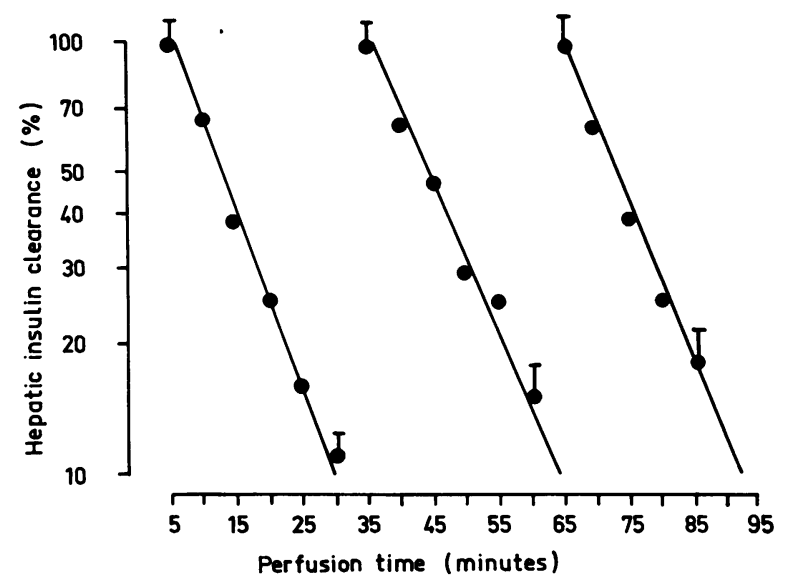

Figure 1. Hepatic insulin clearance as a function of perfusion time. The livers were perfused for three periods, $30 \mathrm{~min}$ each. Insulin was added to the medium at $90 \mu \mathrm{U} / \mathrm{ml}$. Glucose concentration was 5.5 $\mathrm{mM}$. All decay curves followed first order kinetics. The insulin clearance is expressed in percent of the clearance after $5 \mathrm{~min}$ perfusion $(n=6)$. Data are means \pm SEM (represented by bars at 5 and $30 \mathrm{~min}$ ).

these determinations were performed in the first perfusion of the livers of these rats. The heaviest rats showed lower hepatic clearance of insulin than the other groups. These results are expressed per whole liver to remove any effect of liver size on clearance. If, however, the results are expressed per gram liver, the same difference is obtained (not shown).

Effect of FFA on insulin clearance. Fig. $4 a$ shows that insulin clearance was inhibited with increasing FFA concentrations in the perfusate (highest vs. lowest concentrations, $P<0.01$ in both experiments).

Fig. $4 b$ shows the results of the experiments which started with the highest FFA concentration in the perfusate and continued with lower concentrations.

In experiment 1 the inhibited clearance at $712 \mu \mathrm{mol} / \mathrm{liter}(P$ $<0.01$, comparison with the same group of rats at $240 \mu \mathrm{mol} /$ liter in Fig. $4 a$ ) increased during a subsequent perfusion with albumin-free medium, with the final concentration of 240 $\mu \mathrm{mol} / \mathrm{liter} \mathrm{FFA}$, and was now no longer different from the clear-

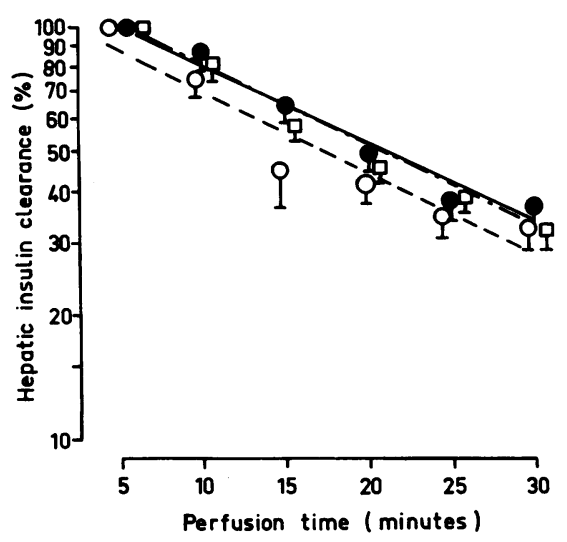

Figure 2. Hepatic insulin clearance at different medium glucose concentrations. (0) $5 \mathrm{mmol} /$ liter glucose. (๑) $10 \mathrm{mmol} /$ liter glucose. ( $\square$ ) $20 \mathrm{mmol} / \mathrm{liter}$ glucose. Insulin was added to the perfusion medium at $300 \mu \mathrm{U} / \mathrm{ml}$. The FFA-concentration was kept constant (550 $\mu \mathrm{mol} /$ liter) throughout the perfusions. The results are means \pm SEM, expressed as in Fig. $1(n=7)$.

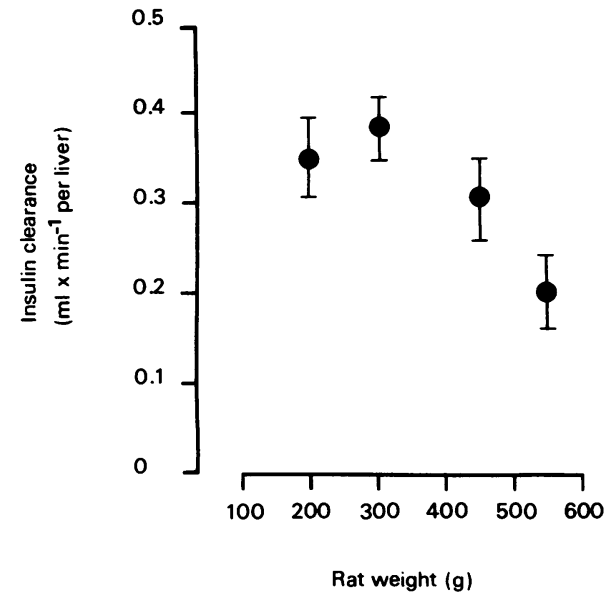

Figure 3. Hepatic insulin clearance in relation to weight (age), of donor rats. Glucose concentration $5.5 \mathrm{mmol} / \mathrm{liter}$ and insulin concentration $211 \mu \mathrm{U} / \mathrm{ml}$. Rat weights (g) and FFA concentrations ( $\mu \mathrm{mol} /$ liter) (within parentheses) were $200 \pm 5(250), 310 \pm 4(240), 460 \pm 5$ (350), and $540 \pm 9(310)$. The number of rats were $6,6,6$, and 5 , respectively. The heaviest rats had significantly $(P<0.05)$ lower clearance than the other rats.

ance when the same FFA concentration was used in the first perfusion (Fig. 4 a).

In experiment 2 very high concentrations of FFA $(2,250$ $\mu \mathrm{mol} /$ liter $)$ also inhibited clearance $(P<0.01$, comparison with the same groups of rats at $350 \mu \mathrm{mol} /$ liter FFA concentration in Fig. $4 a$ ). During the two following perfusions with 1,000 and $350 \mu \mathrm{mol} /$ liter FFA concentration, this inhibition remained. These rats were, however, heavier (older) than those in experiment 1 . When another group of heavy (old) rats were first perfused with FFA concentrations comparable to those in experiment 1 , their low clearance remained at two subsequent perfusions with low FFA concentrations (230 and $190 \mu \mathrm{mol} / \mathrm{liter}$, respectively) (experiment 3 ).

The FFA concentration in the portal vein of the animals in experiment $l(310 \mathrm{~g})$ with intact circulation was $340 \pm 20 \mu \mathrm{mol}$ $(n=6)$.

\section{Discussion}

The in situ perfused rat liver was used to test the influence of different glucose and FFA concentrations on the hepatic insulin clearance. As previously reported $(12,18,19)$ this preparation functions well both in terms of organ integrity and gas exchange over the time period used in the experiments. Insulin clearance by the liver is an exponential function and is dependent on the concentration as also previously reported $(18,19)$. The preparation yielded reproducible results as shown by the clearance in repeatedly performed perfusions with the same liver both at low and high portal insulin concentrations.

Changing the portal glucose concentrations over the range of a normal fasting ( $5 \mathrm{mmol} / \mathrm{liter}$ ) to a high physiological concentration $(20 \mathrm{mmol} / \mathrm{liter})$ did not alter insulin clearance by the liver. This finding is in accordance with other works (2224). These experiments were performed at the FFA concentration of $550 \mu \mathrm{mol} / \mathrm{liter}$. This might be considered as a high physiological concentration (25). Whether glucose had any effect at other FFA concentrations was not tested.

The capacity of hepatic insulin clearance was lower with 


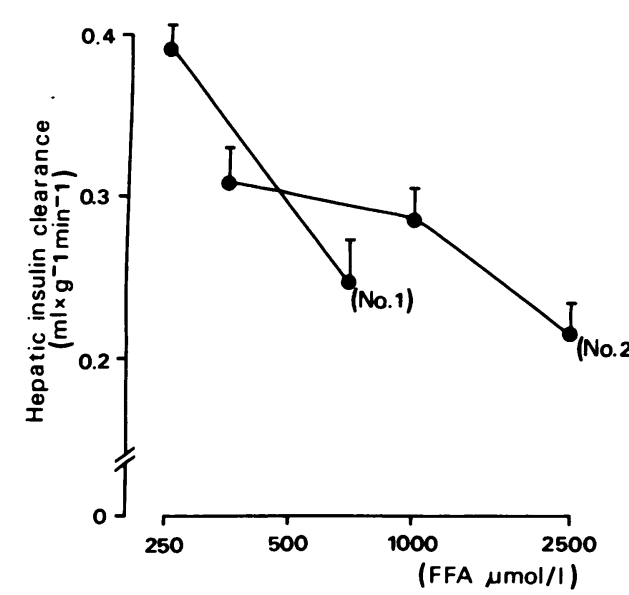

increasing weight (age) of the rats. Animals of 200 and $310 \mathrm{~g}$ average weight showed approximately the same clearance, which then apparently started to decrease at higher weights (ages), significant at a body weight of $540 \mathrm{~g}$ (Fig. 3).

Increasing the FFA concentration of the perfusate markedly reduced the hepatic insulin clearance. This seemed to be most pronounced in the physiological range of portal FFA (300-500 $\mu \mathrm{mol} / \mathrm{liter})(25)$, and amounted to $\sim 40 \%$ (experiment 1 ). It was not possible to design an experiment where perfusate FFA concentrations were kept close to zero, because with FFA-free albumin there was a continuous production of FFA in the system. These FFA were probably derived from the liver, because control experiments showed no increase of FFA concentrations in the perfusate without the liver. It seems likely from the results with a steep inhibition of hepatic insulin clearance from $\sim 250$ to $700 \mu \mathrm{mol} / \mathrm{liter}$ (Fig. $4 a$ ) that hepatic clearance had been higher with FFA concentrations in the perfusate lower than $250 \mu \mathrm{mol} /$ liter. Therefore, the inhibitory effects of FFA on hepatic insulin clearance may well be more pronounced than possible to demonstrate in the present work.

A comparison of experiments 1 and 2 in Fig. $4 a$ shows that the inhibition of clearance was much more pronounced in experiment 1 in the FFA range 240 to $712 \mu \mathrm{mol} /$ liter than in experiment 2 in the range of 350 to $1,000 \mu \mathrm{mol} /$ liter. Although the absolute FFA concentrations are somewhat higher in experiment 2, the increase in FFA concentrations between the both perfusions are somewhat larger in experiment 2 than in 1 (650 vs. $472 \mu \mathrm{mol} / \mathrm{liter}$ ). In spite of this the decrease in insulin clearance was only 0.02 in experiment 2 in comparison with 0.14 in experiment 1 . This difference might well be due to the heavier (older) rats in experiment 2 than in 1 , suggesting that the decrement of insulin clearance by FFA is less pronounced in the livers of heavier (older) rats, which have a lower capacity for insulin clearance at low FFA concentrations (Figs. 3 and $4 a)$.

When perfusions were started with higher FFA concentrations, followed by lower concentrations (Fig. $4 b$ ) the inhibition was released in experiment 1 , but remained in experiment 2 . There are two differences in these studies, the FFA concentrations in the first perfusion were much higher, and the rats heavier (older) in experiment 2 . To distinguish potential effects of both these factors, we performed experiment 3 again with heavy (old) rats, but now with FFA concentrations comparable to those of experiment 1 . The inhibition then remained in spite of two subsequent perfusion periods with essentially fatty acidfree albumin. These results indicate that body weight (age) is a limiting factor for the release of the FFA inhibition of insulin clearance. Whether FFA at very high concentrations had effects in younger (lighter) rats could not be detected because of technical difficulties with the perfusion of livers of small rats with very high FFA concentrations.

In summary, these results show that body weight (age) of the rats not only decreases the capacity, but probably also the sensitivity to, and release of, FFA inhibition of hepatic insulin clearance. This is most probably due to obesity and not to increased age, because it has been possible to restore the insulin binding capacity of isolated hepatocytes from older obese rats to normal levels by fasting the animals (26).

In recent studies we found that fatty acids, in the concentration range inhibiting insulin clearance in the present work, decreased insulin binding, degradation, and function in isolated rat hepatocytes (15), while the number and function of the isolated, solubilized insulin receptors were intact (unpublished observation). The inhibitory effect was counteracted by prevention of fatty acid oxidation by a carnitine-acylCoA transferase inhibitor (16). It seems likely that the inhibitory effect of FFA on hepatic insulin clearance shown in the present work, is explained by these mechanisms, viz., that insulin binding is diminished by fatty acids, and their subsequent oxidation, presumably an effect of insulin receptor internalization/recycling, in agreement with an independent recent report (27). Moreover, we have also found that treating obese (aged) rats with a carnitine-acylCoA transferase inhibitor improves the low insulin binding capacity of the isolated hepatocytes (unpublished observation), again speaking in favor of the importance of FFA oxidation for the reduced hepatic insulin clearance in the obese state.

The immediate metabolic fate of FFA taken up by the liver is mainly a synthesis to triglycerides. From this pool of triglycerides other metabolic steps follow, including fatty acid oxidation (28). Moderately obese rats show a decreased hepatic insulin clearance in proportion to hepatic triglyceride contents, suggesting an inhibitory action of hepatic triglycerides (25). The decreased clearance in heavier, more obese rats in the present work might have been due to a similar mechanism. A limited load of FFA, being oxidized directly or via an expanded triglyc- 
eride pool in the more obese rats would then be expected to have a smaller absolute further effect on blunting insulin clearance, in analogy with the findings in the present work. In addition, the recovery of hepatic insulin clearance after an additional expansion of the hepatic triglyceride pool of obese rats would be expected to be diminished or delayed, which was also observed. The blunted hepatic insulin clearance as well as the effects of FFA on this process in heavier and older rats were thus probably, at least partly, an effect of their relative obesity. This conclusion is supported by recent results showing that inhibition of hepatic fatty acid oxidation in obese rats improves their low hepatic insulin clearance (unpublished observations).

The results of the present work have shown that physiological concentrations of FFA in the portal vein regulate hepatic insulin clearance, in excellent agreement with the observations utilizing isolated hepatocytes. This is a novel observation with potential importance for regulation of hepatic metabolism in the transition between the absorptive and postabsorptive phases. It is already known that gluconeogenesis is dependent on hepatic fatty acid oxidation (for review, see reference 29). The parallel regulation of hepatic insulin uptake seems to be a meaningful mechanism to remove insulin from inhibitory action on hepatic gluconeogenesis.

The applicability of the findings in isolated hepatocytes $(15-17,27)$ and in the perfused liver, reported here, to the situation in vivo must, however, still be regarded with caution, because no direct data are available to address this problem. Although several reports have suggested a decrease of hepatic insulin clearance in obesity in animals (30) and man (31-33) particularly when localized to abdominal regions (6), the methods used in these reports have not always been adequate (34). Furthermore, although increased portal FFA concentrations may have been elevated in these studies, there was probably also a marked portal hyperinsulinemia, which by itself may have influenced on hepatic insulin removal (3-5).

Other potentially confounding factors may be gut factors (35), not included under the experimental conditions employed in the present work. Furthermore, species differences might occur. Before conclusions can be drawn safely about the effects of portal FFA on hepatic insulin clearance in man in vivo in normal and pathological states, direct experimental tests are needed. Such studies seem of considerable interest because of the potential possibility that lipolytically active intraabdominal adipose tissues $(10,11)$ may regulate hepatic insulin clearance, particularly in visceral obesity with its marked peripheral hyperinsulinemia (33).

\section{References}

1. Olefsky, J. M. 1981. Insulin resistance and insulin action: in vitro and in vivo perspectives. Diabetes. 30:148-162.

2. Shapiro, E. T., H. Tillil, A. H. Rubenstein, and K. S. Polonsky. 1988. Peripheral insulin parallels changes in insulin secretion more closely than C-peptide after bolus intravenous glucose administration. J. Clin. Endocrinol. \& Metab. 67:1094-1099.

3. Polonsky, K. S., B. D. Given, L. Hirsch, E. T. Shapiro, H. Tillil, C. Beebe, J. A. Galloway, B. H. Frank, T. Karrison, and E. Van Cauter. 1988. Quantitative study of insulin secretion and clearance in normal and obese subjects. J. Clin. Invest. 81:435-441.

4. Ferrannini, E., J. Wahren, O. K. Faber, P. Felig, C. Binder, and R. A. DeFronzo. 1983. Splanchnic and renal metabolism of insulin in human subjects: a dose-response study. Am. J. Physiol. 244:E517-E527.

5. Rossell, R., R. Gomis, R. Casamitjana, R. Segura, E. Vilardell, and F. Rivera. 1983. Reduced hepatic insulin extraction in obesity: relationship with plasma insulin levels. J. Clin. Endocrinol. \& Metab. 56:608-611.

6. Peiris, A. N., R. A. Mueller, G. A. Smith, M. F. Struve, and A. H. Kissebah.
1986. Splanchnic insulin metabolism in obesity. Influence of body fat distribution. J. Clin. Invest. 78:1648-1657.

7. Sims, E. A. H., E. Danforth, Jr., E. S. Horton, G. A. Bray, J. S. Glennon, and L. B. Salans. 1973. Endocrine and metabolic effects of experimental obesity in man. Recent Prog. Horm. Res. 29:457-490.

8. Björntorp, P., H. Bergman, E. Varnauskas, and B. Lindholm. 1969. Lipid metabolism in relation to body composition in man. Metabolism. 18:840-851.

9. Smith, U. 1980. Adrenergic control of human adipose tissue lipolysis. Eur. J. Clin. Invest. 10:343-344.

10. Rebuffé-Scrive, M., B. Andersson, L. Olbe, and P. Björntorp. 1989. Metabolism of adipose tissue in intraabdominal depots of non-obese men and women Metabolism. 38:453-458.

11. Rebuffé-Scrive, M., B. Andersson, L. Olbe, and P. Björntorp. 1989. Metabolism of adipose tissue in intraabdominal depots in severely obese men and women. Metabolism 39:1021-1025.

12. Assimacopoulos-Jeannet, F., J. H. Exton, and B. Jeanrenaud. 1973. Control of gluconeogenesis and glycogenolysis in perfused livers of normal mice. Am J. Physiol. 225:25-32.

13. Jaspan, J., and K. Polonsky. 1982. Glucose ingestion in dogs alters the hepatic extraction of insulin. In vivo evidence for a relationship between biological action and extraction of insulin. J. Clin. Invest. 69:516-525.

14. Terris, S., and D. F. Steiner. 1976. Retention and degradation of ${ }^{125} \mathrm{I}$-insulin by perfused livers from diabetic rats. J. Clin. Invest. 57:885-896.

15. Svedberg, J., P. Björntorp, U. Smith, and P. Lönnroth. 1990. Free fatty acid inhibition of insulin binding, degradation and action in isolated rat hepatocytes. Diabetes. 39:570-574.

16. Svedberg, J., P. Björntorp, P. Lönnroth, and U. Smith. 1991. Etomoxir prevents the inhibitory effect of free fatty acids on insulin binding and action in isolated rat hepatocytes. Diabetes. 40:783-786.

17. Björntorp, P. 1985. Adipose tissue in obesity (Willendorf lecture). In Recent Advances in Obesity Research. J. Hirsch and T. van Itallie, editors. Libbey, London. 163-168.

18. Mortimore, G. E., F. Tietze, and D. Stettin. 1959. Metabolism of insulin $I^{131}$ studied in isolated perfused rat liver and hind limb preparations. Diabetes. 8:307-314.

19. Wirth, A., G. Holm, and P. Björntorp. 1982. Effect of physical training on insulin uptake by the perfused rat liver. Metabolism. 31:457-462.

20. Hamilton, R. L., M. N. Berry, M. C. Williams, and E. M. Severinghaus 1974. A simple and inexpensive membrane lung for small organ perfusions. $J$. Lipid Res. 15:182-186.

21. Dole, V. P. 1956. A relation between non-esterified fatty acids in plasma and the metabolism of glucose. J. Clin. Invest. 33:150-155.

22. Waldhäusl, W., M. Bratusch, M. P. Gasic, A. Korn, and P. Nowotny 1979. Insulin production rate following glucose ingestion estimated by splanchnic C-peptide output in normal man. Diabetologia. 17:221-227.

23. Olefsky, J., T. Batchelder, S. Colome, and G. Reaven. 1974. Effect of intravenous glucose infusion on plasma insulin removal rate. Metabolism. 23:542-548.

24. Wadell, W., and K. Sussman. 1967. Plasma insulin after diversion of portal and pancreatic venous blood to vena cava. J. Appl. Physiol. 22:808-812.

25. Strömblad, G., and P. Björntorp. 1986. Reduced hepatic insulin clearance in rats with dietary induced obesity. Metabolism. 35:323-327.

26. Frank, H. J. L., and M. B. Davidson. 1982. Insulin binding and action in isolated rat hepatocytes: effect of obesity and fasting. Am. J. Physiol. 243:E240E245.

27. Hennes, M. M. I., E. Shrago, and A. H. Kissebah. 1990. Receptor and postreceptor effects of free fatty acids (FFA) on hepatocyte insulin dynamics. Int. J. Obesity. 14:831-841.

28. Ontko, J. 1972. Metabolism of free fatty acids in isolated liver cells. Factors affecting the partition between esterification and oxidation. J. Biol. Chem. 247:1788-1800.

29. Björntorp, P. 1990. "Portal" adipose tissue as a generator of risk factors for cardiovascular disease and diabetes. Arteriosclerosis. 10:493-497.

30. Karakash, C., F. Assimacopoulos-Jeannet, and B. Jeanrenaud. 1976. An anomaly of insulin removal in perfused livers of obese-hyperglycemic (ob/ob) mice. J. Clin. Invest. 57:1117-1124.

31. Bonora, E., I. Zavaroni, C. Coscelli, and U. Butturini. 1983. Decreased hepatic insulin extraction in subjects with mild glucose intolerance. Metabolism. $32: 438-446$

32. Faber, O. K., K. Christensen, H. Kehlet, S. Madsbad, and C. Binder. 1981. Decreased insulin removal contributes to hyperinsulinemia in obesity. J. Clin. Endocrinol. \& Metab. 53:618-621.

33. Peiris, A. N., R. A. Mueller, G. A. Smith, M. F. Struve, and A. H. Kissebah. 1986. Splanchnic insulin metabolism in obesity. J. Clin. Invest. 76:16481658.

34. Ferrannini, E., and C. Cobelli. 1987. The kinetics of insulin in man. II. Role of the liver. Diabetes Metab. Rev. 3:365-397.

35. Rőjdmark, S., G. Bloom, M. C. Y. Chou, J. Jaspan, and J. B. Field. 1978. Hepatic insulin and glucagon extraction after their augmented secretion in dogs. Am. J. Physiol. 235:E88-E96. 